\title{
Mechanical spring technology improves running economy in endurance runners
}

\author{
KENNETH JAMES RIESS \\ Northern Alberta Institute of Technology, Canada
}

\begin{abstract}
Riess, K.J. (2014). Mechanical spring technology improves running economy in endurance runners. J. Hum. Sport Exerc., 9(4), pp.782-789. In recent years there has been an increase in participation in timed running events. With this increase, the motivation for individuals to run their best has motivated the running shoe industry to make design changes to traditional running foot wear in an effort to improve running economy (RE) and decrease running times. One such design change has been to incorporate mechanical springs (MS) into the midsole of the running shoe. Evaluation of this technology has yet to be performed. This study recruited 17 runners (12 male) and had them run at a submaximal steady state speed for 2 bouts of five minutes at a speed of $3.13 \mathrm{~m} \cdot \mathrm{sec}^{-1}$. The order of shoe condition was randomly assigned and the subjects ran one interval in their own running shoe (OS) and one interval in MS shoes. Metabolic data and heart rate data were averaged over the last three of the five minute efforts. No significant difference was found between MS and OS with regards to shoe weight. Running in MS resulted in lower, non-significant values for steady state ventilation and steady state heart rate. Oxygen consumption was significantly lower in MS compared to OS in both absolute (MS: $2.35 \pm 0.47 \mathrm{~L} \cdot \mathrm{min}^{-1} \mathrm{vs}$. OS: $2.40 \pm 0.473 \mathrm{~L} \cdot \mathrm{min}^{-1}, \mathrm{P}=0.022$ ) and relative (MS: $34.67 \pm 4.35 \mathrm{ml} \cdot \mathrm{kg}^{-1} \cdot \mathrm{min}^{-1} \mathrm{vs}$. OS: $35.34 \pm 4.58 \mathrm{ml} \cdot \mathrm{kg}^{-}$ 1. $\mathrm{min}^{-1}, \mathrm{P}=0.033$ ) terms. Running in shoes fitted with MS technology improves running economy over OS and this technology may assist athletes achieve their best running times. Key words: STEADY STATE OXYGEN CONSUMPTION, RUNNING SHOEM, RUNNING PERFORMANCEMIDSOLE.
\end{abstract}

Corresponding author. Northern Alberta Institute of Technology, 11762106 St NW, Edmonton, AB T5G 3H6, Canadá.

E-mail: kennethr@nait.ca

Submitted for publication June 2014

Accepted for publication October 2014

JOURNAL OF HUMAN SPORT \& EXERCISE ISSN 1988-5202

(C) Faculty of Education. University of Alicante

doi:10.14198/jhse.2014.94.05 


\section{INTRODUCTION}

Participation in timed running events has grown in the United States over the past 2 decades with 15.5 million reported finishers in running events in the US in 2012 (Running USA, 2013). Reasons for participating in these endurance activities may vary from health benefits, such as reduction in risk for diseases that are the result of physical inactivity, to motivation derived from completing a specific race distance in as short a time as possible (Hart 2013).

Improving running speed, and in the process achieving personal a best, is based on several factors. Physiological aspects, such as increased maximal oxygen consumption (VO2max) (Noakes et al. 1990; Billat et al. 2001) and increased anaerobic threshold relative to VO2max (Farrell et al. 1979; Tanaka et al. 1984) have been associated with success in running. However, the ability for an individual to achieve their full potential in endurance sports is also based on running economy (RE) (di Prampero et al. 1986; Daniels et al. 1992; Saunders et al. 2004), defined as the steady-state oxygen consumption $\left(\mathrm{VO}_{2}\right)$ required to maintain a submaximal running speed (Lacour et al. 1990; Santos-Concejero et al. 2014).

The relationship between RE and performance has been well documented (Lacour et al. 1990; Di Prampero et al. 1993; Saunders et al. 2004). Di Prampero et al. (1993) reported that a 5\% improvement in RE elicited a 3.7\% improvement in endurance running performance. This improvement in RE may be the result of specific training (Franch et al. 1998; Barnes et al. 2013) or ergogenic factors, such as a reduction in shoe mass (Frederick 1984; Divert et al. 2008; Franz et al. 2012), as Frederick (1984) found that an increase in shoe mass of $100 \mathrm{~g}$ per foot can reduce RE by $1 \%$.

In an attempt to improve RE, several manufacturers have made modifications to the traditional running shoe design. These companies have returned to a more "natural" running design with the minimal shoe, having little or no cushioning. The effect of this style of shoe on RE has been evaluated (Squadrone et al. 2009; Perl et al. 2012). These studies reported a significant improvement in RE. Specifically, Perl et al. (Perl et al. 2012) compared running in a minimal shoe condition to the more traditional cushioned footwear. While accounting for weight and stride frequency, they reported that running in the minimal condition was $2.4 \%$ to $3.3 \%$ economical than the cushioned shoe, depending on the foot strike pattern. Spira Footwear (El Paso, Texas. USA) has also modified the traditional running shoe with in insertion of three mechanical springs (MS) (Figure 1A.) into the midsole of the shoe (Figure 1B) (two in the forefoot and one in the heel).

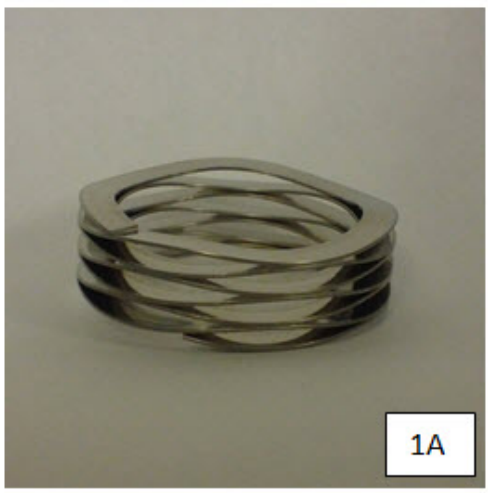

Figure 1. (1A) Mechanical spring; a "crest to crest" spring design incorporated into the heel and forefoot

(1B) of experimental shoe

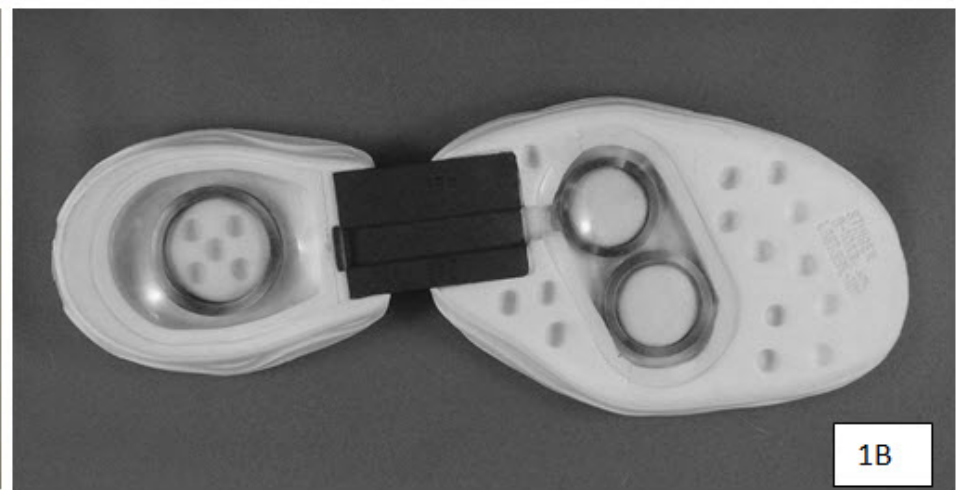


The effect on RE of a mechanical spring has not been reported in the literature. Accordingly, the purpose of this study was to determine if the incorporation of 3 mechanical springs into the midsole of a running shoe will improve RE when compared to endurance runner's own shoe of choice. Further, we hypothesized that $\mathrm{RE}$ will be improved as a result of this MS technology.

\section{MATERIAL AND METHODS}

\section{Participants}

This study was approved by the Author's institutional research ethics board. Subjects for the study were recruited from the local running community in the Author's home city between September, 2013 and January, 2014. Inclusion criteria for subjects in the study involved males and females, free of running injury, over the age 18 years and with the ability to give informed consent. Potential subjects were screened for risk of exercise complications with the completion of a Par-Q+ (Warburton et al., 2011). Finally, the subjects for the study were required to run comfortably (ie. achieve VO2ss) on an un-cushioned treadmill at a speed of $3.13 \mathrm{~m} \cdot \mathrm{sec}-1$ with a $0 \%$ grade.

A total of 17 subjects (males $=12$, females $=5$ ) were recruited for the study. The subjects had a reported a running training history of $10.4( \pm 8.5)$ years. Descriptive statistics of the subjects can be found in Table 1 .

Table 1. Subject descriptive data

\begin{tabular}{ll}
\hline Measure & Mean ( \pm SD) \\
\hline Age (years) & $34.4 \pm 12$ \\
Height (cm) & $174.3 \pm 7.4$ \\
Weight (kg) & $66.0 \pm 11.4$ \\
Training History (years) & $11.1 \pm 8.8$ \\
\hline
\end{tabular}

\section{Measures}

To assess the effect of MS on RE, we measured steady state oxygen consumption $\left(\mathrm{VO}_{2 S s}\right)$ while subjects ran at $3.13 \mathrm{~m} \cdot \mathrm{sec}^{-1}$ on an un-cushioned treadmill to mitigate the any contribution the treadmill cushioning may have on RE. This velocity was selected as a constant pace as this speed would be sub-maximal for the runner volunteers and, as such, would allow for attainment of a physiological steady state. Subjects ran in two different shoe conditions, their personal running shoe of choice (OS) and in a model of shoe outfitted with MS (Spira Stinger XLT). The primary outcome of this study was to assess the difference in VO2SS consumption of the MS shoe compared to OS.

\section{Procedures}

Upon arrival to the laboratory, the principal investigator explained the study design and requirements to the subjects and subjects were presented with an information letter summarizing the requirements for participation in the study. After reading the information letter and given the opportunity to ask questions or gain clarification the subjects then signed an informed consent. 
Anthropometric measures included height and weight and were recorded with the subjects in bare feet and wearing light weight running clothes. Gender and running history (years of running training) were also recorded. The subjects were then connected to an ambulatory metabolic measurement system (K4b2, Cosmed, Rome, Italy) which recorded breath by breath measure of expired gas as well as heart rate via a wireless chest strap. The metabolic system was calibrated for air flow and gas analysis, as per manufacturer's instructions, before each assessment.

Subjects were then sized for the best fit of MS shoe based on their own preference and the left shoe of both the OS and MS were weighed to the nearest gram. Subjects then performed a brief, standardized warm up consisting of a light run at $2.24 \mathrm{~m} \cdot \mathrm{sec}^{-1}$ for one minute, followed by $2.68 \mathrm{~m} \cdot \mathrm{sec}^{-1}$ for one minute and finally $3.13 \mathrm{~m} \cdot \mathrm{sec}^{-1}$ for one minute. The warm up was completed in the OS. Upon completion of the warm up, the subject rested for five minutes and the order of shod condition for the study was randomized with the use of randomization software (Handy Randy, Steven's Creek Software, Cupertino CA). At the completion of the rest period, the subjects were directed to the treadmill for the first of two 5 minutes runs in the different shoe conditions. Each five minute run was followed by five minutes of rest, at which time the shoes were exchanged for alternate condition. After the final five minutes steady state session, subject we allowed to cool down as per their own direction.

Analysis

Statistical analyses were performed using MedCalc for Windows, version 12.5 (MedCalc Software, Ostend, Belgium). Descriptive data are presented as mean ( \pm standard deviation). Physiological data obtained from the three conditions were analyzed using a Paired T-Test comparing the MS to OS. Statistical significance for this study was set, a priori, at $\mathrm{P}<0.05$.

Metabolic data and heart rate data were collected during the five minute runs and during the rest period. During the last three minutes of steady state exercise breath by breath and heart rate data were isolated and averaged to ensure only steady state values for ventilation $\left(\mathrm{VE}_{\mathrm{ss}}\right)$, heart rate $\left(\mathrm{HR}_{\mathrm{ss}}\right)$ and $\mathrm{VO}_{2 \mathrm{ss}}$ were included in the analysis.

\section{RESULTS}

\section{Shoe Characteristics}

No significant difference was observed between single shoe weight in OS and MS (OS: $277.4 \pm 66.8 \mathrm{~g}$ vs. MS: $276.8 \pm 27.5 \mathrm{~g}, \mathrm{P}=0.97)$.

\section{Physiological Variables}

A summary of steady state physiological comparisons can be found in Table 2. Running in the shoe equipped with MS elicited a lower, non-significant, $\mathrm{HR}_{\mathrm{ss}}$ (OS: $145 \pm 14$ beats $\min -1$ vs. MS: $143 \pm 14$ beats.min-1, $P=0.100$ ) and VE $E_{s s}(O S: 69.35 \pm 11.38 \mathrm{~L} \cdot \min -1$ vs. MS: $68.08 \pm 10.18 \mathrm{~L} \cdot \mathrm{min}-1, \mathrm{P}=0.126)$ in the MS compared to OS. However, a significant reduction in $\mathrm{VO}_{2 S s}$, both relative to body weight (Figure 2) and absolute, was observed in MS compared to OS. 
Table 2. Comparison of mechanical spring shoes to subjects' own shoe

\begin{tabular}{lrlc}
\hline Measure & Mechanical & Own Shoe & P \\
& Spring & & \\
& & & \\
\hline $\mathrm{HR}_{\mathrm{SS}}\left(\right.$ beats $\left.\cdot \mathrm{min}^{-1}\right)$ & $143.4( \pm 14.1)$ & $145.1( \pm 14.4)$ & 0.094 \\
$\mathrm{VE}$ & & \\
& $68.1( \pm 10.2)$ & $69.3( \pm 11.4)$ & 0.126 \\
$\mathrm{VO}_{2 \mathrm{SS}}\left(\mathrm{L} \cdot \mathrm{min}^{-1}\right)$ & $2.35( \pm 0.466)$ & $2.40( \pm 0.473)$ & $\left.0.022^{-1}\right)$ \\
$\mathrm{VO}_{2 \mathrm{SS}}\left(\mathrm{ml} \cdot \mathrm{kg}^{-1} \cdot \mathrm{min}^{-1}\right)$ & $34.67( \pm 4.35)$ & $35.34( \pm 4.58)$ & $0.033^{*}$
\end{tabular}

* Indicates a significance difference mechanical spring shoe and own running shoe, $\mathrm{P}<0,05$

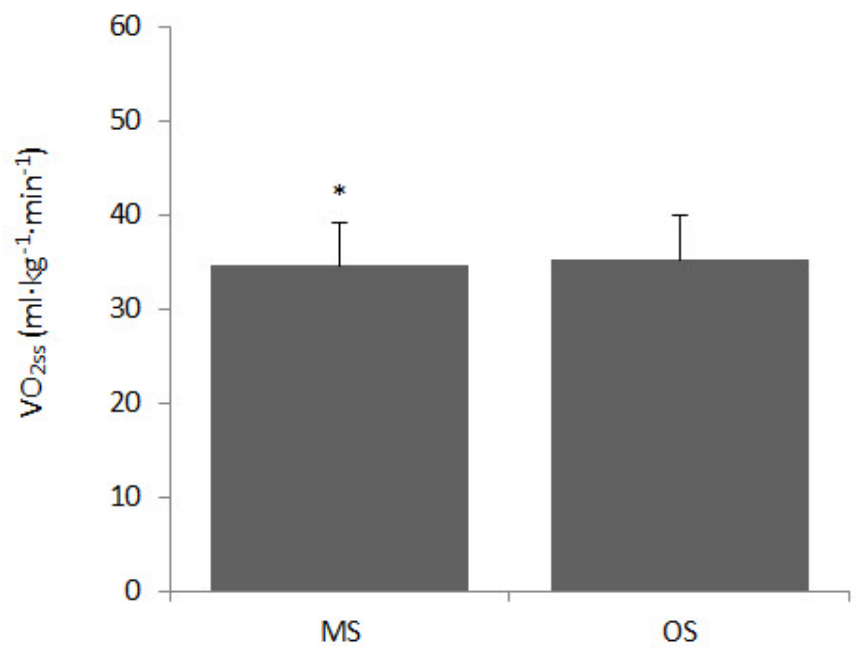

* Indicates a significant difference between Mechanical Spring shoe (MS) from own running shoe (OS), P < 0.05

Figure 2. $\mathrm{VO}_{2 s s}$ in different shoe conditions during running intervals

\section{DISCUSSION}

The major new finding of this study was that running shoes, which incorporated MS significantly improved RE during submaximal running in recreational runners compared with their current running shoe of choice. To our knowledge, this is the first study that has assessed improvements in running economy using this technology.

Shoe weight has been reported to have an effect on RE (Frederick 1984; Jones et al. 1984) and determined that a lower shoe weight is related to a significant improvement in running economy. Frederick (1984) reported that while running, there is a $1 \%$ improvement in economy for every $100 \mathrm{~g}$ per foot 
reduction in shoe weight. The finding that a the $\mathrm{O} 2$ cost of running was $1 \%$ lower in the MS equipped shoes would indicate this design of running shoe has the economy benefits of a lighter weight shoe. This improved economy may lead to lower (ie. improved) times in endurance races as Conley and Krahenbuhl (1980) reported that greater running economy has a strong relationship to $10 \mathrm{~km}$ running time.

In recent years there has been a trend toward light weight, "minimal" running shoes to improve performance and reduce injury (Murphy et al. 2013). This minimal model of shoe has demonstrated a lower $\mathrm{O} 2$ cost of running associated with it due to its light weight and nominal cushioning. Perl et al. (2012) reported that running in the minimal running shoe reduced the 02 requirement of running at $3.0 \mathrm{~m} \cdot \mathrm{s}^{-1}$ by $2.41 \%$ to $3.32 \%$, even after accounting for shoe mass. We extend the finding of this study by reporting that improvements in running economy can also be obtained in running shoes with a more traditional shock absorbing midsole. This may be of benefit for recreational runners as improvements obtained without the possible increase risk of injury that has been reported in transitioning to running in minimal shoes (Salzler et al. 2012a).

As well as having the benefit to running economy similar to that of the minimal shoe, the MS equipped shoe maintains the cushioning benefit of heavier shoes. Indeed, lighter weight, minimal shoes are related to increased risk of injury in runner (Salzler et al. 2012b; Ryan et al. 2013). Specifically, Ryan et al. (Ryan et al. 2013) reported on 99 recreational runner training for a $10 \mathrm{~km}$ event. Upon completion of the training, those runners training in the traditional "neutral" shoe reported the fewest amount of injuries compared with the partial minimalist and minimalist shoe. Evidently, though not an outcome of this study, effective cushioning in the shoe is important in the reduction in risk for running injuries.

\section{LIMITATIONS}

This study reports an improvement in RE resulting from running in shoes with MS compared to OS, however, we acknowledge limitations with our study design. While, on average, we observed a significant improvement in running economy, there was considerable variability in the improvement, with some subjects having greater running economy in their own shoe. Future research in this area would be beneficial to determine what factors may result in improved RE in the MS shoe.

Secondly, we allowed the runners to run in their preferred running shoe. While all of the running shoes used by the participants were traditional "cushioned" running shoes manufactured by major running shoe companies, there was an assortment of makes and models. While there was no significant difference in shoe weight between OS and MS, we could not control for the amount of training done on the shoe and the breakdown of the condition of the midsole. However, the runners in this study were all serious recreational runners who ran in lower mileage, good condition footwear.

Finally, we evaluated RE at a preset pace, indoors and on an uncushioned treadmill with no grade applied. This may limit the transferability to RE while competing in an outdoor road race, which is where such events occur.

\section{CONCLUSIONS}

Running shoes with integrated MS technology may have the benefit of lower oxygen cost for running at a submaximal effort while offering the injury reduction benefit of cushioning. The use of this make of running 
shoe by serious recreational runners may result in improved performances in endurance running events. For example, an improvement of $1 \%$ in RE has been reported to produce an increase in running speed of approximately $0.049 \mathrm{~m} \cdot \mathrm{sec}^{-1}$ (Hanson et al. 2011). Applying this information to shoes outfitted with MS technology, a marathon runner could expect to save over 6 minutes on their finishing time in over running in their OS.

\section{ACKNOWLEDGEMENTS}

The author would like to thank the participants that took part in this study for their generous donation of their time and also thank Dr. Mark Haykowsky for his insight and advice during the preparation of this manuscript. This study did not receive funding from Spira Footwear, however, Spira Footwear kindly donated the shoes necessary to evaluate the MS technology.

\section{REFERENCES}

1. Barnes, K.R., Hopkins, W.G., McGuigan, M.R., \& Kilding, A.E. (2013). Effects of different uphill interval-training programs on running economy and performance. Int J Sports Physiol Perform 8, pp.639-47.

2. Billat, V.L., Demarle, A., Slawinski, J., Paiva, M., \& Koralsztein, J.P. (2001). Physical and training characteristics of top-class marathon runners. Med Sci Sports Exerc, 33, pp.2089-97.

3. Conley, D.L., \& Krahenbuhl, G.S. (1980). Running economy and distance running performance of highly trained athletes. Med Sci Sports Exerc, 12, pp.357-60.

4. Daniels, J., \& Daniels, N. (1992). Running economy of elite male and elite female runners. Med Sci Sports Exerc, 24, pp.483-9.

5. di Prampero, P.E., Atchou, G., Bruckner, J.C., \& Moia, C. (1986). The energetics of endurance running. Eur J Appl Physiol Occup Physiol, 55, pp.259-66.

6. Di Prampero, P.E., Capelli, C., Pagliaro, P., Antonutto, G., Girardis, M., Zamparo, P., \& Soule, R.G. (1993). Energetics of best performances in middle-distance running. J Appl Physiol (1985),74, pp.2318-24.

7. Divert, C., Mornieux, G., Freychat, P., Baly, L., Mayer, F., \& Belli, A. (2008). Barefoot-shod running differences: shoe or mass effect? Int J Sports Med, 29, pp.512-8.

8. Farrell, P.A., Wilmore, J.H., Coyle, E.F., Billing, J.E., \& Costill, D.L. (1979). Plasma lactate accumulation and distance running performance. Med Sci Sports, 11, pp.338-44.

9. Franch, J., Madsen, K., Djurhuus, M.S., \& Pedersen, P.K. (1998). Improved running economy following intensified training correlates with reduced ventilatory demands. I Amelioration de I ' economie de course consecutivement a un entrainement intensif correle avec des besoins ventilatoires reduits. Medicine \& Science in Sports \& Exercise, 30, pp.1250-1256.

10. Franz, J.R., Wierzbinski, C.M., \& Kram, R. (2012). Metabolic cost of running barefoot versus shod: is lighter better? Med Sci Sports Exerc, 44, pp.1519-25.

11. Frederick, E.C. (1984). Physiological and ergonomics factors in running shoe design. Appl Ergon, 15, pp.281-7.

12. Hanson, N.J., Berg, K., Deka, P., Meendering, J.R., \& Ryan, C. (2011). Oxygen cost of running barefoot vs. running shod. Int J Sports Med, 32, pp.401-6.

13. Hart, L. (2013). Marathon-Related Cardiac Arrest. Clinical Journal of Sport Medicine, 23, pp.409410. 
14. Jones, B.H., Toner, M.M., Daniels, W.L., \& Knapik, J.J. (1984). The energy cost and heart-rate response of trained and untrained subjects walking and running in shoes and boots. Ergonomics, 27, pp.895-902.

15. Lacour, J.R., Padilla-Magunacelaya, S., Barthelemy, J.C., \& Dormois, D. (1990). The energetics of middle-distance running. Eur J Appl Physiol Occup Physiol, 60, pp.38-43.

16. Murphy, K., Curry, E.J., \& Matzkin, E.G. (2013). Barefoot running: does it prevent injuries? Sports Med, 43, pp.1131-8.

17. Noakes, T.D., Myburgh, K.H., \& Schall, R. (1990). Peak treadmill running velocity during the VO2 max test predicts running performance. J Sports Sci, 8, pp.35-45.

18. Perl, D.P., Daoud, A.I., \& Lieberman, D.E. (2012). Effects of footwear and strike type on running economy. Med Sci Sports Exerc, 44, pp.1335-43.

19. Ryan, M., Elashi, M., Newsham-West, R., \& Taunton, J. (2013). Examining injury risk and pain perception in runners using minimalist footwear. Br J Sports Med.

20. Salzler, M.J., Bluman, E.M., Noonan, S., Chiodo, C.P., \& de Asla, R.J. (2012b). Injuries observed in minimalist runners. Foot Ankle Int, 33, pp.262-6.

21. Santos-Concejero, J., Granados, C., Irazusta, J., Bidaurrazaga-Letona, I., Zabala-Lili, J., Tam, N., \& Gil, S.M. (2014). Influence of the biomechanical variables of the gait cycle in running economy. I Influencia de variables biomecánicas del ciclo de paso en la economía de carrera. RICYDE. Revista Internacional de Ciencias del Deporte, 10, pp.95-108.

22. Saunders, P.U., Pyne, D.B., Telford, R.D., \& Hawley, J.A. (2004). Factors affecting running economy in trained distance runners. Sports Med, 34, pp.465-85.

23. Squadrone, R., \& Gallozzi, C. (2009). Biomechanical and physiological comparison of barefoot and two shod conditions in experienced barefoot runners. J Sports Med Phys Fitness, 49, pp.6-13.

24. Tanaka, K., \& Matsuura, Y. (1984). Marathon performance, anaerobic threshold, and onset of blood lactate accumulation. J Appl Physiol Respir Environ Exerc Physiol, 57, pp.640-3.

25. Running USA. (2013). State of the Sport - Part III: U.S. Race Trends. From from http://www.runningusa.org/annual-reports.

26. Warburton, D.E., Jamnik, V.K., Bredin, S.S., McKenzie, D.C., Stone, J., Shephard, R.J., \& Gledhill, N. (2011). Evidence-based risk assessment and recommendations for physical activity clearance: an introduction. Appl Physiol Nutr Metab, 36(Suppl 1), pp.S1-2. 